\title{
Análise de discurso de gênero em Silicone Blues
}

\author{
Gender discourse analysis in Silicone Blues
}

\section{Análisis del discurso de género en Silicone Blues}

\section{Recebido: 06/01/2018 \\ Aprovado: 15/08/2018 \\ Publicado: 05/11/2018}

\author{
Rafael De Tilio ${ }^{1}$ \\ Maria Teresa de Assis Campos ${ }^{2}$ \\ Izabella Lenza Crema ${ }^{3}$ \\ Juliana Machado Ruiz ${ }^{4}$
}

O objetivo dessa pesquisa foi compreender os efeitos de sentidos produzidos sobre gênero em quatro tirinhas da série Silicone Blues da cartunista Laerte. O corpus de análise foi constituído por quatro tirinhas sobre transgeneridade da série, analisadas a partir da Análise do Discurso de Michel Pêcheux. Essa pesquisa, de caráter qualitativa, foi realizada entre janeiro e abril de 2014. Silicone Blues, através do humor, propicia reflexões e critica a lógica heteronormativa compulsória que articula como indissociados: o sexo (biologia), o gênero (determinação de atitudes de homens e mulheres) e a orientação heterossexual (atração por pessoas do mesmo sexo) pressupondo características fixas, imutáveis e diferenciais para homens e mulheres. No entanto, Silicone Blues não rompe definitivamente com a heteronormatividade, mas se apresenta como uma pièce de résistance transgênera, ou seja, um desafio ao que se estipula como normal para os sujeitos.

Descritores: Identidade de gênero; Pessoas transgênero; Direitos civis.

The objective of this research was to understand the effects of meanings produced on gender in four comic strips of the series Silicone Blues by cartoonist Laertes. The corpus of analysis was composed of four comic strips of the series on transgender, analyzed from Michel Pêcheux Discourse Analysis by. This research, of qualitative character, was held between January and April, 2014. Silicone Blues, through humor, propitiates reflections and criticizes the compulsory heteronormative logic that articulates as undissociated: sex (biology), gender (determination of attitudes of men and women) and heterosexual orientation (attraction by people of same sex) presupposing fixed, immutable and differential characteristics for men and women. However, Silicone Blues does not definitely break with the heteronormativity, but it presents itself as a transgendered pièce de résistance, that is, a challenge to what is stipulated as normal for the subjects.

Descriptors: Gender identity; Transgender persons; Civil Rights.

El objetivo de esta investigación fue comprender los efectos de los sentidos producidos sobre el género en cuatro tiras cómicas de la serie Silicone Blues del caricaturista Laerte. El corpus de análisis consistió en cuatro tiras cómicas sobre Transgeneridad de la serie, analizadas a partir del análisis de discurso de Michel Pêcheux. Esta investigación, de carácter cualitativo, se realizó entre enero y abril de 2014. Silicone Blues, a través del humor, propicia reflexión y critica la lógica heteronormativa obligatoria que articula como no disociados: sexo (biología), género (determinación de actitudes de hombres y mujeres) y orientación heterosexual (atracción por personas de mismo sexo) suponiendo características fijas, inmutables y diferenciales para hombres y mujeres. Sin embargo, el Silicone Blues no rompe definitivamente con el heteronormatividad, sino que se presenta como un Pièce de Résistance transgénero, es decir, un desafío a lo que se estipula como normal para los sujetos.

Descriptores: identidad de género; Personas transGénero; Derechos civiles.

\footnotetext{
1. Psicólogo. Mestre e Doutor em Psicologia. Docente do Departamento de Psicologia e do Programa de Pós-Graduação em Psicologia (PPGP) da Universidade Federal do Triângulo Mineiro (UFTM), Uberaba, MG, Brasil. ORCID: 0000-0002-4240-9707 E-mail: rafaeldetilio.uftm@gmail.com

2. Psicóloga. Mestre em Psicologia. Docente do Departamento de Saúde Coletiva da UFTM, Uberaba, MG, Brasil. ORCID: 0000-0001-5955-7397 E-mail: mtassiscampos@hotmail.com

3. Psicóloga. Mestre em Psicologia. Psicóloga do Centro de Atenção Psicossocial Álcool e Drogas da Secretaria Municipal de Saúde de Uberaba, MG, Brasil ORCID: 0000-0001-6929-8579 E-Mail: bella_lenzacrema@hotmail.com

4. Psicóloga. Mestranda do PPGP-UFTM. ORCID: 0000-0002-0895-5253 E-mail: julianamruiz@hotmail.com
} 


\section{INTRODUÇÃO}

$\mathbf{M}$ ais do que a variedade das posições e/ou fantasias sexuais (conscientes ou inconscientes) a sexualidade é um dispositivo instaurado a partir do Século XVIII composto por inúmeros discursos (médicos, jurídicos, pedagógicos e familiares) que regulam as relações entre os corpos, tornando-se palco de análises e intervenções consideradas adequadas ou desviantes à verdade sobre o sexo ${ }^{1}$. Um dos principais aspectos da regulação da sexualidade é o gênero: mecanismo que define o feminino e masculino e suas relações ${ }^{1,2}$.

Neste sentido, a sexualidade (scientia sexualis) pautou-se na diferença tanto biológica dos corpos (sexo) quanto das atitudes esperadas de homens e mulheres (gênero) como as maneiras históricas, e culturais organizadoras das relações sociais ${ }^{2,3}$. Gênero, portanto, resulta de práticas políticas, econômicas e sociais cujo interesse é manter a ordem social (e os privilégios), cristalizando e naturalizando os sujeitos como homens ou como mulheres portadoras de características físicas, psicológicas e sociais consideradas inalteráveis ${ }^{2}$ Assim, se padrões de normalidade de gênero são fixados, isso significa não tolerar sexo(s) ou gênero(s) destoante(s).

Portanto, a sexualidade na sociedade ocidental moderna é tida como normal quando heterossexual, na vida adulta, visando à reprodução biológica e quando sexo e gênero dos sujeitos estão coadunados cisheteronormatividade ${ }^{3}$. Aos transgêneros (aqueles não adequados à heteronormatividade) reservam-se as exclusões, discriminações e intervenções corretivas $^{2}$.

Além do mais, por causa da sua condição de gênero destoante do considerado normal, os transgêneros são expostos à transfobia: diversas violências ocorridas no ambiente doméstico e no espaço público expressas em crimes de ódio (assassinatos, torturas, lesões corporais graves, violências sexuais, discriminações e preconceitos), dificuldades de acesso ao mercado de trabalho formal e à educação e saúde públicas que resultam em danos para a saúde física e mental, além da recusa da autodeterminação de gênero e da sexualidade ${ }^{4,5}$.

Apesar da limitação na produção de dados e índices oficiais por parte dos agentes públicos governamentais sobre a transfobia no Brasil6, entidades nacionais e internacionais não-governamentais ${ }^{4,7}$ estimam que este seja o país mais transfóbico e transviolento do mundo, decorrendo em grave problema de saúde pública. A transgeneridade no Brasil é uma condição de risco e de vulnerabilidade social ${ }^{8}$ mesmo após a promulgação da Política Nacional de Saúde de Saúde Integral LGBT e outras leis que pretendem proteger essa população $0^{9,10}$.

Ademais, a sexualidade (e, consequentemente, o gênero) é produzida por diversas tecnologias sociais, isto é, pelas concepções e práticas consideradas normais que difundem como homens e mulheres devem ser, pensar, agir e se relacionar ${ }^{3}$. Dentre as tecnologias sociais de gênero destacam-se as mídias de massa (rádio, televisão, jornais e internet) e também as artes, literatura e, dentre elas, as histórias em quadrinhos ${ }^{11,12}$.

Se os gêneros são efeitos (resultados) das tecnologias sociais da sexualidade que pretendem estabelecer padrões atitudinais da heteronormatividade para homens e mulheres, eles igualmente podem ser compreendidos como atos performatizados (desempenhados) pelos sujeitos.

Em outras palavras, ser homem ou mulher não é uma decorrência da biologia (sexo), mas sim o exercício de atitudes em cumprimento aos padrões normativos estabelecidas historicamente (das quais decorrem orientações e expectativas específicas a depender do sexo do sujeito) que a todo momento devem ser reafirmadas pelos sujeitos e que, por isso, devido à sua exaustiva reiteração, criam a ilusão da naturalidade, quando na realidade não o são ${ }^{2,3}$.

Portanto, ao dar visibilidade e problematizar as inúmeras possibilidades transgêneras (e/ou de autodeterminação de gênero), pode-se questionar os modelos heteronormativos e heterossexistas contemporâneos dos quais decorrem 
violências entre homens, mulheres e transgêneros ${ }^{13}$. Assim, o objetivo dessa pesquisa foi compreender os efeitos de sentidos produzidos sobre gênero em quatro tirinhas da série Silicone Blues da cartunista Laerte.

\section{MÉTODO}

Trata-se de uma pesquisa qualitativa cuja coleta e análise foi realizada entre janeiro e abril de 2014, utilizando fontes documentais (imagens, mais precisamente tirinhas de histórias em quadrinhos) da série Silicone Blues da cartunista brasileira Laerte, analisados por meio da Análise do Discurso de Michel Pêcheux.

Acerca do referencial teórico é significativo destacar que a análise do discurso (AD) para Michel Pêcheux se preocupa com qualquer materialidade linguística (escrita, oral, gráfica e outras) que produza efeitos de sentidos entre os interlocutores ${ }^{14}$. Estes efeitos de sentidos não são criados individualmente, e são resultados de processos coletivos, simbólicos e históricos que lhes são anteriores e constitutivos. Os sentidos dependem das condições materiais da sua produção, isto é, de quem, quando e como se diz e o que já foi dito, dentre outros fatores ${ }^{14}$.

Para a $\mathrm{AD}$, os efeitos de sentidos são dependentes da linguagem, que é o lugar da manifestação da Ideologia (apagamento da historicidade das relações entre os sujeitos, resultando na suposta naturalização da produção dos sentidos) e das ideologias (conjuntos de representações mais ou menos estáveis e em disputa pelos grupos) ${ }^{14-16}$. Isso significa que as marcas constitutivas dos sentidos são esquecidas e consideradas óbvias ou naturais para os interlocutores que, por sua vez, acreditam ser autores e origens dos sentidos quando, na realidade, há um arcabouço anterior (de sentidos) que permitem ou vetam esta ou aquela significação ${ }^{16}$.

As ilusões de autoria dos sentidos e de dominância dos discursos ocorrem porque a linguagem constitui os sujeitos a partir de dois processos inconscientes aos interlocutores, denominados "Esquecimento Número 1" (ilusão de que o sujeito é a causa do que é dito, quando é efeito dos posicionamentos históricos, sociais, situacionais e ideológicos que interpelam os interlocutores) e "Esquecimento Número 2" (ilusão de que a única maneira de exprimir algo é unicamente com as exatas palavras que foram utilizadas) ${ }^{14}$.

De modo igual, além do (que é) dito e das possibilidades/impossibilidades do dizer, o que não foi dito também participa do processo de significação - o que é dito e o não-dito são denominados na $\mathrm{AD}$ de interdiscurso ${ }^{14}$. Portanto, os sentidos presentes no intradiscurso (o que é dito) são determinados pelo interdiscurso.

Assim, a partir de uma conjuntura social e histórica determinada, que comporta valores e sentidos de referências (Formação Ideológica - FI; no caso, a sociedade de produção capitalista), as palavras/expressões/termos mudam de sentido a depender das posições sociais daqueles que as empregam (Formação Discursiva - FD), determinando o que pode ou não pode ser dito. Portanto, numa FI há várias FD. E dentro da sua FD de referência os interlocutores (automática e inconscientemente na tentativa de estabilizar seus discursos) se pautam em antecipações dos sentidos (dos seus e) dos interlocutores, ao que se denomina Formação Imaginária $(\text { Fim })^{14,16 .}$

Em suma, há estreitas correlações entre a Ideologia, ideologias, FI, FD e FIm nos discursos dos interlocutores que compõem os sentidos ${ }^{14,16}$. Para a $A D$, não é o falante que usa a linguagem, mas sim a linguagem que usa o falante: a Ideologia interpela o indivíduo em sujeito, e por interpelação ideológica compreende-se a sobredeterminação inconsciente (não individual, mas coletiva) dos sentidos ${ }^{14,17}$.

É a partir deste conjunto conceitual (denominado dispositivo teórico) que os analistas do discurso visam compreender como a linguagem afeta a produção de sentidos entre os interlocutores. Ao escolher o material linguístico com o qual pretendem trabalhar e quais conceitos da AD mobilizarão para compreender sua produção de sentidos, 
os analistas do discurso delimitam seu dispositivo analítico, havendo (potencialmente) tantos dispositivos analíticos quantos analistas, inclusive sem haver obrigatoriedade da utilização de todo dispositivo teórico ${ }^{14,16,18 .}$

Em relação ao que se denomina procedimentos de coleta e de análise dos dados, o seguinte percurso seria utilizado numa $\mathrm{AD}$ : a partir de uma materialidade linguística qualquer (corpus) são consideradas as incidências do interdiscurso e do Esquecimento Número 2 na composição dos efeitos dos sentidos (dessuperficialização do corpus, ou transposição do material linguístico para objeto discursivo) e, após isso, são consideradas as influências das FD, FIm, FI e do Esquecimento Número 1 (análise do processo discursivo) no contexto de produção do objeto discursivo ${ }^{14,16,19}$.

\section{RESULTADOS}

Os dados (materialidade linguística) desta pesquisa estão compostos por quatro (de um total de seis) tirinhas da cartunista Laerte sobre transgeneridade na série Silicone Blues. A opção por não analisar toda a série se deu em razão de que duas delas não tratarem sobre relações de/entre gênero e transgeneridade.

Essa série foi originalmente publicada no formato impresso em 1992 e reproduzida em formato digital em 2009. Silicone Blues versa sobre os questionamentos de identidade de gênero de um personagem (Hugo) que antecipa outra produção (Eu, Travesti, de 2008) e personagem (Muriel Total, de 2009, uma crossdresser alter-ego da Laerte) no seu processo de transgenerificação.

As tirinhas selecionadas foram as seguintes:

Figura 1. Tirinha 1 da série Silicone Blues.

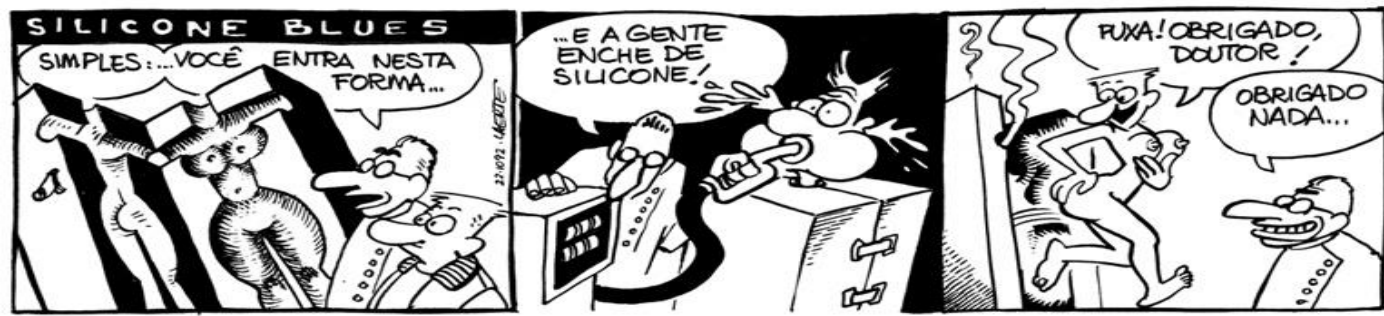

Fonte: http://murieltotal.zip.net/arch2009-03-01_2009-03-07.html

Figura 2. Tirinha 2 da série Silicone Blues.

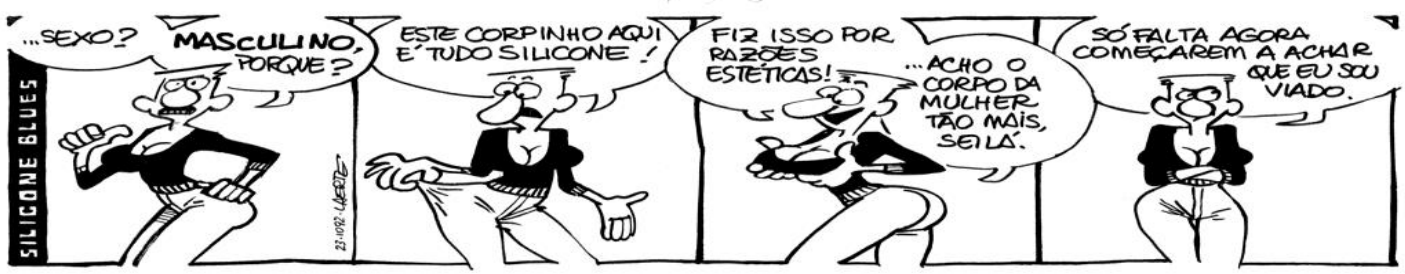

Fonte: http://murieltotal.zip.net/arch2009-03-08_2009-03-14.html

Figura 3. Tirinha 4 da série Silicone Blues.

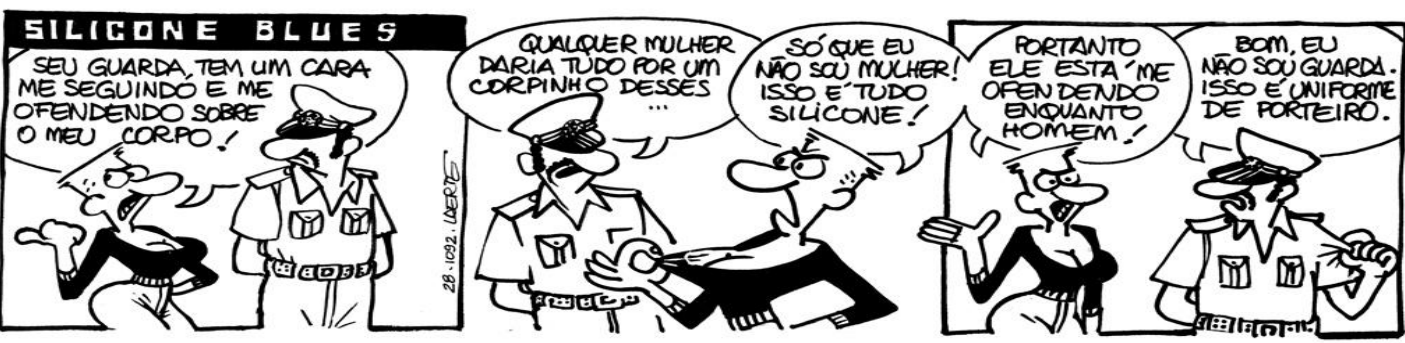

Fonte: http://murieltotal.zip.net/arch2009-03-08_2009-03-14.html 
Figura 4. Tirinha 6 da série Silicone Blues.

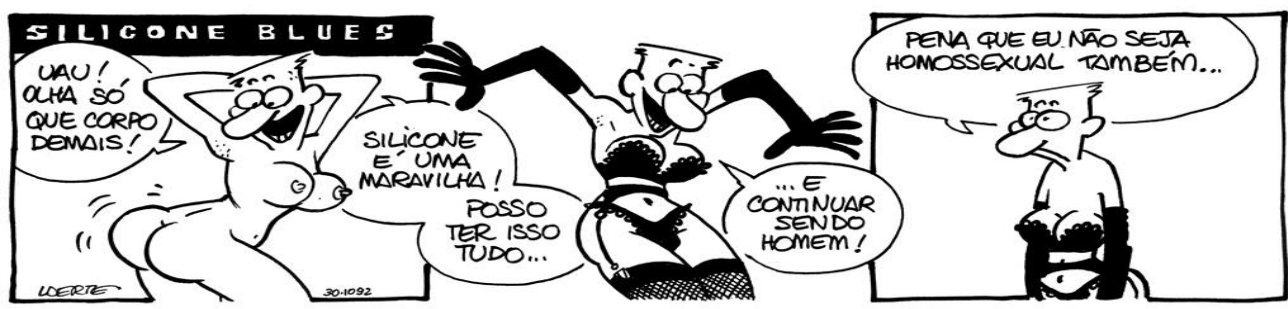

Fonte: http://murieltotal.zip.net/arch2009-03-08_2009-03-14.html

\section{DISCUSSÃO}

A partir dos corpora (materialidade linguística - cada um dos quatro corpus de tirinhas) que compõem este dispositivo analítico, a $\mathrm{AD}$ sobre transgeneridade em Silicone Blues ocorrerá em dois momentos: (1) produção do objeto discursivo e (2) considerações sobre o processo discursivo.

É importante destacar que nesta análise não se trata de localizar uma origem de uma temática recorrente na obra da cartunista (as questões de gênero) ${ }^{20-22}$, mas sim produzir no vasto arquivo da cartunista uma mobilização de recorte de sequências discursivas ${ }^{23}$ articuladas ao tema da transgenerificação.

\section{Produção do objeto discursivo}

A primeira tirinha (Figura 1) é composta por três imagens que mostram Hugo (protagonista) iniciando sua transgenerificação junto a outro personagem, que por sua vez maneja uma máquina assemelhada a uma bomba de posto de gasolina. De início, destaca-se a simplicidade da transgenerificação: basta entrar em uma máquina (ambiente tecnológico) composta por um molde (de um corpo feminino idealizado na contemporaneidade) e preenchê-lo com silicone para resultar em modificações.

Injetar silicone industrial visando transformar o corpo masculino em feminino (produzindo seios e glúteos avantajados) é prática comum entre transexuais, transgêneros e travestis, mas coloca a saúde em risco por causa da elevada probabilidade de ocorrência de infecções e rejeições ${ }^{24}$, o que desmistifica a simplicidade e inocuidade deste processo representado na tirinha.

Na Figura 1 pode-se observar uma FD que coaduna a estética do corpo à expressão do gênero e à orientação sexual dos sujeitos, já que é subentendido que há um formato específico a ser observado de corpo masculino e outro de corpo feminino. Além disso, o uso da palavra "forma" (instrumento capaz de fazer a adequação dos objetos/sujeitos a um ideal) no primeiro quadrinho da tirinha faz supor que haja um corpo ideal a ser assumido.

Essa FD possibilita supor que Laerte critica o modo simplista como são produzidos os sentidos acerca das constituições de gênero e sexualidade: reduzir as construções das identidades de gênero à constituição biológica/estética dos sujeitos seria fenômeno semelhante à ilusão da transparência da linguagem, que supõe que os sentidos estão "colados" nas palavras ${ }^{16}$. No caso, feminino e masculino seriam (supostamente) inerentes à formatação dos corpos que apresentariam características distintas para cada um dos gêneros.

Ainda na Figura 1, em momento nenhum, nem antes e nem depois da transformação, é mencionado o sexo ou gênero de Hugo, pois a única vez em que o "doutor" se refere ao personagem ele o chama de você, pronome de tratamento que é neutro. Isso pode ser compreendido como uma limitação (ou, em outras palavras, uma impossibilidade de dizer) nesta FD (heteronormativa e binária ${ }^{2}$ ) para designar um sujeito que possui corpo feminino e/com um pênis - já que a emasculação não é realizada na tirinha. Isso exemplifica como as produções de sentidos sobre gênero estão condicionadas às $\mathrm{FD}$ e $\mathrm{FI}^{16}$ que ditam quem/como se pode ser ou homem ou mulher. Um corpo feminino com pênis não encontra respaldo nesta FD e, portanto, é impossível.

Outro aspecto relevante é que Hugo denomina seu interlocutor de "doutor", ou seja, detentor de um saber. 0 interdiscurso permite aproximar doutor de médico, 
especialista para o qual se deve confessar a própria sexualidade e gênero para que ela possa ser aferida e, se for o caso, corrigida ${ }^{1}$. Ademais, Hugo ao situar seu interlocutor em posição de poder, automaticamente se situa como incapaz de decidir a respeito do seu próprio corpo ${ }^{1}$. Outro exemplo da preponderância do discurso médico sobre sexualidade e gênero é a patologização dos transgêneros, alvos de diversas intervenções (hormonais, cirúrgicas e psicológicas) ${ }^{25}$.

Outra questão denunciada na Figura 1 diz respeito à diferença de tratamento do doutor para com Hugo antes e depois da sua passagem pela máquina. Após Hugo agradecer, o doutor responde incutindo um implícito de cobrança ("Obrigado nada...") com um olhar e sorriso maliciosos, remetendo a uma erotização entre um homem (doutor) e um corpo (concebido como) de mulher (Hugo).

Tal mudança direcionada a Hugo após assumir um corpo feminino demonstra que são as FI que balizam as produções de sentidos entre os interlocutores ${ }^{14,16}$ : é a partir dos sentidos produzidos ao longo da história sobre a reificação do corpo feminino ${ }^{26}$ que o doutor se posiciona (significa) e é posicionado (significado). Logo, o doutor sugere que (a posse de) o corpo feminino pode ser moeda de troca pela transformação.

Outro efeito de sentido na Figura 1 é o transbordamento: a segunda imagem mostra Hugo dentro da máquina sendo preenchido com silicone que escapa dos seus ouvidos. Não há como desconsiderar que as tecnologias (de constituição) dos gêneros são controladas por homens e das quais resultam preços a serem pagos pelas mulheres - suposto na terceira imagem: o pagamento tem conotação sexual.

Essa FD em relação à heteronormatividade compulsória é importante porque estabelece os parâmetros para as produções de sentidos entre os interlocutores: um transgênero (Hugo) só pode ser modificado por um homem da ciência que cobra seu preço. E a suposta naturalização desta FD (que imbrica uma FI da personagem) que é explicitada no agradecimento de Hugo ("Puxa! Obrigado, doutor") que não menciona nem os custos nem as consequências para tais tecnologias, aproximando (imaginariamente) a transgenerificação a uma ação volitiva e consciente.

Remeter a transgenerificação a uma simplicidade deste porte pode ser assemelhado ao funcionamento do Esquecimento Número 2 e do interdiscurso ${ }^{14}$ (ilusão de que a única maneira de falar algo é com as exatas palavras que foram utilizadas). Por exemplo, na terceira imagem da tirinha 1 , Hugo, ao invés de dizer "Puxa! Obrigado, doutor!", poderia ter dito "Puxa! Quanto custa, doutor?", ou ainda "Puxa! Obrigado, senhor!". 0 funcionamento do interdiscurso esclarece que se outras palavras tivessem sido utilizadas, outros seriam os efeitos de sentidos produzidos ${ }^{16}$.

A segunda tirinha (Figura 2) é composta por quatro imagens: Hugo dialoga com seu interlocutor acerca das razões pela transgenerificação e algumas das suas preocupações. É possível considerar na Figura 2 críticas as três variáveis constitutivas dos sujeitos: sexo, gênero e orientação sexual. Rememorando, sexo seria uma inscrição prédiscursiva, natural e biológica dos sujeitos designada ao nascer (tendo como principal referência as genitálias); gêneros seriam os papéis decorrentes da diferença sexual; e, a orientação sexual seria o desejo dos sujeitos e com quem eles se relacionam romântica e/ou eroticamente ${ }^{2,8}$.

É possível considerar que Hugo produz efeitos de sentido junto aos seus interlocutores (ocultos) que pretendem questionar os encadeamentos heteronormativos que associam sexo/gênero/orientação sexual. Isso fica evidente quando ele se (auto) nomeia do sexo masculino ao mesmo tempo em que se mostra portador de um corpo feminino e questiona sua orientação sexual. Hugo, ao mesmo tempo em que reafirma e enaltece (pois em negrito na imagem) seu sexo, indaga as razões da desconfiança e explicita ao interlocutor do que se trata (tudo é silicone, ou seja, artificial) e quais são suas justificativas pela transgenerificação (razões estéticas e interesse pelo corpo das mulheres, isto é, heterossexualidade). 
Mas ele igualmente destaca o incômodo da transgenerificação ("Só falta agora acharem que eu sou viado"). Os efeitos de sentido na Figura 2 (dentre os quais se destacam a afirmação de gênero, a admiração pelo corpo feminino e a preocupação com o julgamento alheio) podem aludir como um contraponto à Figura 1, já que aquela não mencionava as motivações e preocupações da transgenerificação.

A presença do interdiscurso se evidencia na Figura 2: na primeira imagem Hugo responde a um interlocutor oculto $(\mathrm{o} / \mathrm{s}$ leitor/es), mas não se sabe qual foi a pergunta realizada, e mesmo se houve pergunta. De qualquer maneira, o mais significativo é que o interlocutor está fora da cena: por meio deste recurso evidencia-se que o efeito de sentido não é controlado pelo falante (Hugo), mas ocorre na interação entre interlocutores ${ }^{14}$, o que destaca o caráter socialmente precedente da linguagem nos discursos (e na formação dos efeitos de sentidos).

Essa resposta de Hugo é uma antecipação imaginária ${ }^{27}$ correspondente a uma FI do protagonista inserida numa FD específica que enaltece a heteronormatividade compulsória e estranha a um sujeito que contenha ao mesmo tempo pênis, seios e glúteos femininos. Assim, imaginariamente, só ser um "viado" (termo pejorativo para o homossexual masculino) ou um outsider da heteronormatividade. Poderse-ia supor que a resposta de Hugo comportaria várias possíveis perguntas, tais como: "Qual é o seu sexo/gênero?", e/ou "De qual sexo/gênero você gosta?", ao que ele responde "Masculino, porque?", podendo ser isso tanto seu sexo/gênero quanto sua predileção (orientação sexual).

A segunda e a terceira imagens da Figura 2 revelam a artificialidade do (seu) corpo: $e$ feito de silicone, resultado de interesses estéticos e admiração pelo corpo feminino. Nisto, o interdiscurso permite considerar que Hugo possui interesse tanto em ter um corpo feminino para manter relações afetivas e sexuais (remetendo à última imagem da sequência) quanto ser um corpo feminino sem ser denominado homossexual. 0 intradiscurso (o que Hugo diz) está repleto de outros dizeres e de não-ditos - de interdiscurso ${ }^{14,16 .}$

Outra maneira de abordar a artificialidade constitutiva dos corpos pelo sexo (biologia) é utilizar o conceito de performatividade: reiteração das atitudes (ações, pensamentos e sentimentos) que estabelecem a ilusão da coerência entre sexo (aspectos biológicos) e gênero (aspectos culturais) e orientação sexual ${ }^{2,13}$. Essa nãonaturalidade (performatividade) dos corpos seria própria da constituição dos gêneros, e pode ser visualizada na tirinha 4 (Figura 3) composta por três imagens que mostram uma conversa entre Hugo transgenerificado e outro personagem.

A Figura 3 pode ser compreendida como uma resposta à tirinha anterior (Figura 2), na qual Hugo questionava se achariam ser ele "viado". Hugo informa a um guarda que está sendo ofendido verbalmente por causa do seu corpo (de mulher), mas novamente não se sabe quais foram as ofensas.

0 guarda responde questionando às razões do inconformismo do/da protagonista, sugerindo que Hugo (por ter um corpo ideal de feminilidade) deveria agradecer por ser alvo de ofensas que, na realidade, são expressões dos interesses dos homens lembrando que Hugo explicita que foi um cara (homem) que lhe ofendeu.

Isso revela um interessante efeito de sentido numa FD heteronormativa: o domínio masculino e a submissão/passividade feminina. Essa FD circunscreve os interlocutores (cisgnênero/guarda; transgênero/Hugo) e determina seus dizeres e os sentidos das suas palavras, haja vista que Hugo explicita seu inconformismo por ter sido confundido/assemelhado a uma mulher quando, na realidade, é um homem. Aliás, a última imagem da Figura 3 permite entrever, por vias do interdiscurso, que o designativo homem se refere tanto ao autodeclarado gênero (masculino) quanto à espécie (humano, portador de direitos).

E é na última imagem daquela tirinha (da Figura 3) que o humor se revela. Ao dizer que não deveria ser vítima de violência por ser da espécie humana (e, assim, homens, mulheres e transgêneros deveriam possuir 
direitos), o guarda revela que é um porteiro, fazendo menção ao seu uniforme. 0 uniforme do porteiro metaforiza o corpo de Hugo, pois se um porteiro pode se passar por guarda por causa do uniforme (performatividade), Hugo pode se passar por homem mesmo tendo corpo de mulher - questionando a articulação sexo, gênero e orientação sexual da heteronormatividade compulsória ${ }^{13}$.

Mas ao declinar de sua posição discursiva de guarda e passar para a de porteiro, pode-se compreender sua falta de interesse em proteger os sujeitos não adequados à heteronormatividade. Isso exemplifica o conceito de discurso em AD: efeitos de sentidos entre os interlocutores dependem de suas condições materiais de produção ${ }^{14}$.

A quarta e última tirinha (Figura 4), que é a sexta da série Silicone Blues, mostra novamente em três imagens a satisfação e frustração de Hugo com a transgenerificação. Nas duas primeiras imagens, Hugo atesta a satisfação com a transgenerificação e continuar sendo homem com seios e glúteos avantajados e usar lingerie feminina ao mesmo tempo em que (na última imagem da cena) revela sua frustração.

Dentre os possíveis efeitos de sentidos produzidos há o enaltecimento dos resultados da tecnologia prostética (de gênero) do silicone que moldela o corpo conforme a vontade do personagem, aproximando-o do universo feminino ao mesmo tempo em que isso lhe causa consternação.

Assim, a imagem 3 na Figura 4 permite indagar quem desejaria Hugo com corpo transgenerificado de mulher. A resposta e seu sentido (FIm) só pode ser configurada numa FD específica (heteronormativa): apenas um homem não adequado à heteronormatividade poderia desejar outro homem (Hugo) travestido e transgenerificado que, ainda assim, se considera homem - daí a lamentação.

0 resultado da susposta liberdade de gênero representado pela transgeneridade não é a satisfação plena, mas a preocupação, a inadequação e a exclusão. 0 discurso sobre sexualidade que delimita como normal a heteronormatividade (homens ou mulheres, cujas características psicológicas e sociais devem estar adequadas às determinaçoes biológicas) equivale a situar a transgenerificação não como a resolução do binarismo de/entre os gêneros, mas sim como uma problematização da naturalização do binarismo de gênero ${ }^{2}$.

Todavia, esse efeito de sentido poderia ser outro, caso Hugo considerasse que mulheres também podem se interessar por corpos de mulheres ou por corpos híbridos e fronteiriços (seios e glúteos protuberantes mais pênis), mas devido a FD heteronormativa essa constituição de sentido é vetada, pois o interdicurso está composto pelo dito, pelo não-dito, pelos silenciamentos e pelos impossíveis de dizer que atingem os interlocutores em determinadas $\mathrm{FD}^{14,16}$. No caso do Silicone Blues, as tirinhas 6 (Figura 4) e 2 (Figura 2) evidenciam que sob as prédicas da heterormatividade compulsória apenas sujeitos desajustados da norma (no caso, "viados") podem desejar sujeitos transgenerificados, pois ambos são desviantes.

\section{Sobre o processo discursivo}

Para a $\mathrm{AD}$ a compreensão do processo discursivo pretende explicitar as condições materiais de produção dos sentidos, ou seja, quais são as principais FD, FIm e FI concernentes à produção dos discursos ${ }^{14,16,19}$. Isso poderia ser resumido à compreensão de como o Esquecimento Número 1 interpela a produção dos sentidos entre os interlocutores.

O Esquecimento Número 1 remete à ilusão (constitutiva) de que o sujeito é a causa e origem do que é dito e dos sentidos, sendo esse processo também denominado de esquecimento ideológico - o apagamento da Ideologia na constituição subjetiva ${ }^{14}$. Na AD, é importante compreender que a Ideologia interpela os indivíduos (ente material sem história) em sujeitos (ente social e histórico), situando-os em FD específicas. Essa interpelação é um processo inconsciente aos sujeitos e, assim, é importante destacar a(s) influência(s) da Ideologia e da(s) ideologia(s) na constituição dos sentidos 17,19,28.

Reitera-se que Silicone Blues foi produzida e publicada por Laerte em 1992, e 
está disponível desde 2009 no site oficial da cartunista na seção da personagem crossdresser Muriel. Em relação à cartunista, Laerte Coutinho nasceu em 1951 e foi considerada uma das mais influentes cartunistas brasileiras desde a década de 1970 quando profissionalizou sua produção de histórias em quadrinhos, tendo recebido inúmeros prêmios pela sua obra, que cada vez mais versa sobre temas políticos e de direitos das minorias sexuais ${ }^{11,29,30}$.

Em 2000, Laerte começou efetivamente seu processo de transgenerificação (uso de roupas íntimas e vestimentas femininas; depilação íntima; crescimento de unhas e de cabelos). Antes disso, na adolescência, teve alguns poucos relacionamentos homoafetivos (com homens) motivados por curiosidade, mas depois teve esposa e filhos. Apesar disso, sempre se sentiu um homem-estranho.

Em 2004 criou a personagem crossdresser Muriel a partir de outro personagem (Hugo). Em 2010 revelou publicamente sua condição transgênero e, em 2012, foi uma das fundadoras da ABRAT (Associação Brasileira de Transgêner@s) e passou a defender abertamente a causa transgênero. Segundo relatou em diversas entrevistas, sua transgenerificação foi dificultosa e gerou vários conflitos individuais, familiares e públicos. Laerte se autodenomina transgênero, e faz questão de que lhe reconheçam no feminino.

Ela não se denomina travesti/crossdresser (homem que se veste de mulher) ou transexual (não vê nenhum problema em ter pênis, e não pretende realizar a cirurgia de redesignação sexual, apesar de não desconsiderar implantar seios de silicone), além de autorreferir sua orientação sexual como heterossexual e homossexual ao mesmo tempo. Segundo a cartunista, ela é um homem que, mesmo aproximada performativamente do feminino, se interessa exclusivamente por mulheres cisgênero (biologicamente nascidas mulheres e que se identificam subjetivamente com este sexo) e, por isso, diz que pode ser designada como lésbica ${ }^{11,29,30}$.

Uma frase que bem representa a obra da Laerte é "ridendo castigat mores" (o humor corrige/castiga os costumes) ${ }^{30}$. Castigare significa tornar casto e rever preconceitos (no caso, os de gênero) por vias do humor. E talvez essa seja a principal FIm de Silicone Blues: utilizar o sarcasmo e a ironia para evidenciar as opressões dos (trans) gêneros.

Não à toa, o título (Silicone Blues) e os conteúdos da série por ele produzida e analisada nesta pesquisa remetem tanto a uma tecnologia social da sexualidade (uso do silicone), que produz sujeitos transgêneros, quanto a um sentimento de tristeza (blues), que faz referência a um estilo musical de cunho melancólico, mesmo que sua intenção seja produzir humor.

Essa FIm está inserida e é componente de uma FD já especificada: o posicionamento possível de uma cartunista transgênero na heteronormatividade compulsória. Essa heteronormatividade estabelece e delimita um sistema de dois sexos (machos e fêmeas) e dois gêneros (homens e mulheres) que deveriam estar em adequação e complementaridade (macho/homem versus porém necessitando de fêmea/mulher) ${ }^{2}$ - em outros termos: cisnormatividade ou cissexualidade - sendo os transgêneros considerados moralmente desviantes ou doentes.

Supõe-se que mesmo questionando e problematizando essa FD, Silicone Blues não rompe com os binarismos de sexo e de gênero. Tampouco poderia fazer isso, pois, no geral, a performatividade de gênero ocorre de maneira naturalizada e sem questionamento pelos performers ${ }^{2}$, sendo um processo inconsciente e incontrolável por parte dos sujeitos, tal como opera o Esquecimento Número $1^{14}$.

Neste contexto de FD acerca da heteronormatividade compulsória, a FI (que é a conjuntura social e histórica) da contemporaneidade e que circunscreve Silicone Blues é o sistema de produção capitalista17,28. Em suma, questionar a cissexualidade e a cisgeneridade só pode ser proveniente de sujeitos desajustados ${ }^{1,29}$.

\section{CONCLUSÃO}

Diante do material linguístico proposto para análise nesta pesquisa, torna-se possível 
destacar os efeitos de sentidos que ora possibilitam questionamentos à heteronormatividade compulsória que circunscreve os discursos, e ora denunciam os óbices (discursivos) dos mesmos.

Considerando a linguagem enquanto mecanismo que situa os interlocutores na FI vigente (heteronormativa) e enquanto dispositivo de controle e de poder, Silicone Blues, através do humor, propicia indagações a respeito da lógica (heteronormativa) que articula e pressupõem indissociáveis o sexo, o gênero e a orientação (hetero) sexual. No entanto, ao mesmo tempo em que o faz, denuncia as limitações da linguagem para reconhecer sujeitos que fogem à (suposta hetero) norma.

A despeito da significativa inserção, reconhecimento e sucesso social da Laerte no cenário de produção artística e de tecnologias de gênero, Silicone Blues deve ser considerado não um rompimento, mas uma pièce de résistance transgênera, ou seja, um desafio ao que se estipula como normal para os gêneros. Isso auxilia a compreender porque nas tirinhas Hugo sempre retorna a indagar acerca das consequências da sua transgenerificação ao mesmo tempo em que a concebe como um passe de mágica, uma simples intervenção científica ou uma escolha consciente.

Nesse sentido, apesar de consideráveis os efeitos de sentidos potencialmente questionadores sobre gênero presentes em Silicone Blues (pois os reais interlocutores são os leitores), eles devem ser considerados dentro de um escopo mais amplo que apenas o do humor: a FI (e as FD e as FIm dos/nos discurso) do contemporâneo está assentada em diferenciações e assimetrias de gênero e de poder entre os interlocutores, quer sejam homens e/ou mulheres, sendo difícil visualizá-las e, mais ainda, rompê-las.

\section{REFERÊNCIAS}

1. Foucault M. História da sexualidade: a vontade de saber. Rio de Janeiro: Paz e Terra; 2014. v.1, $175 \mathrm{p}$.

2. Butler J. Problemas de gênero: feminismo e subversão da identidade. Rio de Janeiro: Civilização Brasileira; 2015. 238p.
3. De Lauretis T. A tecnologia de gênero. In: Holanda HB, organizadora. Tendências e impasses: o feminismo como crítica cultural. Rio de Janeiro: Rocco; 1994, p. 206-242.

4. LaGata C [Balzer C], Beredo L. Informe anual del TMM 2016 [Internet]. Berlin: Transrespect versus Transphobia Worldwide; o Transgender Europ; 2016 [citado em 16 nov 2016]. 27p. (Serie de Publicaciones TvT; 15). Disponível em: https://transrespect.org/wpcontent/uploads/2016/11/TvT-PS-Vol152016.pdf

5. Jesus JG. Orientações sobre identidade de gênero: conceitos e termos: guia técnico sobre pessoas transexuais, travestis e demais transgêneros, para formadores de opinião [Internet]. Brasília, DF: Ed. do Autor; 2012 [citado em 16 nov 2016]. Disponível em: http://www.sertao.ufg.br/uploads/16/original_ ORIENTA\%C3\%87\%C3\%95ES_POPULA\%C3\%87 \%C3\%830_TRANS.pdf?1334065989

6. Ministério das Mulheres, da Igualdade Racial e dos Direitos Humanos (Brasil). Relatório de violência homofóbica no Brasil: ano 2013 [online]. Brasília, DF: Secretaria Especial de Direitos Humanos; 2016. [citado em 16 nov 2016]. Disponível em: http://www.saude.sp.gov.br/resources/ses/perfi l/cidadao/homepage-new/outros-

destaques/lgbt-comite-tecnico-de-saudeintegral/textos-tecnicos-e-

cientificos/relatorio_violencia_homofobica_2013. pdf

7. Nogueira SNB, Aquino TA, Cabral EA. Dossiê: a geografia dos corpos das pessoas trans [Internet]. Brasil: Rede Trans Brasil; 2017. [citado em 28 jan 2017]. Disponível em: https://storage.googleapis.com/wzukusers/user31335485/documents/5a468580e124dwhI7Exh /redetransbrasil_dossier.pdf

8. Peres WS, Toledo LG. Dissidências existenciais de gênero: resistências e enfrentamentos ao biopoder. Rev Psicol Polít. 2011; 11(22):261-77.

9. Ministério da Saúde (Br). Portaria no 2.836, de 1ำ de Dezembro de 2011. Institui, no âmbito do Sistema Único de Saúde (SUS), a Política Nacional de Saúde Integral de Lésbicas, Gays, Bissexuais, Travestis e Transexuais (Política Nacional de Saúde Integral LGBT) [Internet]. Brasília, DF: Ministério da Saúde; 2011 [citado em 27 jan 2017]. Disponível em: http://bvsms.saude.gov.br/bvs/saudelegis/gm/2 011/prt2836_01_12_2011.html

10. Brasil. Decreto n. 8.727, de 28 de abril de 2016. Dispõe sobre o uso do nome social e o reconhecimento da identidade de gênero de 
pessoas travestis e transexuais no âmbito da administração pública federal direta, autárquica e fundacional [Internet]. D.O.U.,Brasília, DF, 29 de abr 2016 [citado em 27 jan 2017]. Disponível em: http://www.planalto.gov.br/ccivil_03/_Ato20152018/2016/Decreto/D8727.htm

11. Teodoro HGS, Cogo D. Comunicação e transgeneridade: a imagem midiática do crossdressing na experiência de Laerte Coutinho. Temática. 2015; 11(7):84-100.

12. Vargas AL. A invenção dos quadrinhos autorais: uma breve história da arte da segunda metade do século XX. História, Histórias. 2016; 4(7):25-37.

13. Graça R. Performatividade e política em Judith Butler: corpo, linguagem e reivindicação de direitos. Perspect Filos. 2016; 43(1):21-38.

14. Pêcheux M. Semântica e Discurso: uma crítica à afirmação do óbvio. Campinas: UNICAMP; 2014. $317 \mathrm{p}$.

15. Martins SO. Análise do discurso. RCA, Rev Cient Ajes. 2011; 2(3):67-76.

16. Orlandi EP. Análise do discurso: princípios e procedimentos. Campinas: Pontes; 2013. 100p.

17. Althusser L. Ideologia e aparelhos ideológicos do Estado (notas para uma investigação). In: Zizek Z, organizador. Um mapa da ideologia. Rio de Janeiro: Contraponto; 2010. p. 105-143.

18. Maingueneau D. A análise do discurso e suas fronteiras. Matraga. 2007; 14(20):13-37.

19. Gomes AMT. Do discurso às formações ideológicas e imaginárias: análise do discurso segundo Pêcheux e Orlandi. Rev Enferm UERJ. 2007; 15(4):555-62.

20. Soares AFS. A construção da identidade sexual: travesti, a invenção do feminino. EID\&A. 2012; 2:5-14.

21. Pessoa DS. "Eu sou gente!". Representações d@s (tr@ns) gêneros em veículos midiáticos - o caso Laerte Coutinho. [dissertação]. Viçosa, MG: Universidade Federal de Viçosa; 2015. 162p.

22. Alencar M. A invasão dos piratas do Tietê. In: Mendes T, organizador. Humor paulistano: a experiência da Circo Editorial. São Paulo: SESI-SP; 2014. p. 337-405.

23. Kogawa J. Qual via para a análise do discurso?: uma entrevista com Jean-Jacques Courtine. Alfa. 2015; 59(2):407-17.

24. Campuzano G. Recuperação das histórias travestis. In: Cornwall A, Jolly S. Questões de sexualidade: ensaios transculturais. Rio de Janeiro: ABIA; 2008. p. 100-132.

25. Rocha MV, Sá IR. Transexualidade e o direito fundamental à identidade de gênero. RIDB. 2013; 2(3):2337-64.

26. Lourenço ACS, Artemenko NP, Bragaglia AP. A objetificação feminina na publicidade: uma discussão sob a ótica dos estereótipos. In: XIX Congresso de Ciências da Comunicação na Região Sudeste; Vila Velha, ES; 2014. São Paulo: Intercom; 2014. p.1-15.

27. Pêcheux M. Análise automática do discurso (AAD69). In: Gadet F, Hak T, organizadores. Por uma análise automática do discurso: uma introdução à obra de Michel Pêcheux. Campinas: UNICAMP; 1997. p. 61-161.

28. Pêcheux M. 0 mecanismo do (des)conhecimento ideológico. In: Zizek Z, organizador. Um mapa da ideologia. Rio de Janeiro: Contraponto; 2010. p. 143-152.

29. Moura AG. Sobre corpos, sexo, desejo e performatividade: a desconstrução de gênero nos trabalhos de Laerte. Fronteras, Rev Ciênc Soc Humanid. 2014; 1(2):5-22.

30. Barros FS. Laerte em trânsito: como vive, como pensa e com quem anda o cartunista que decidiu ser mulher em caráter experimental. Piauí. 2013; 79:16-25.

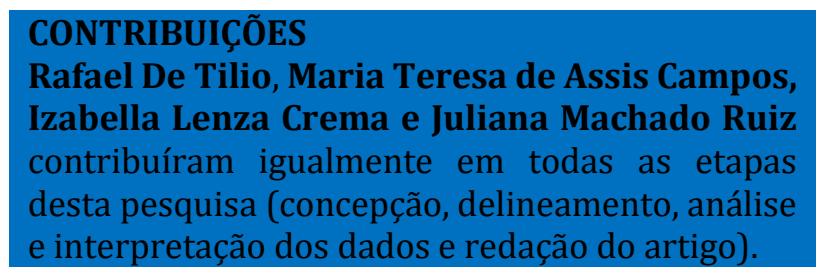

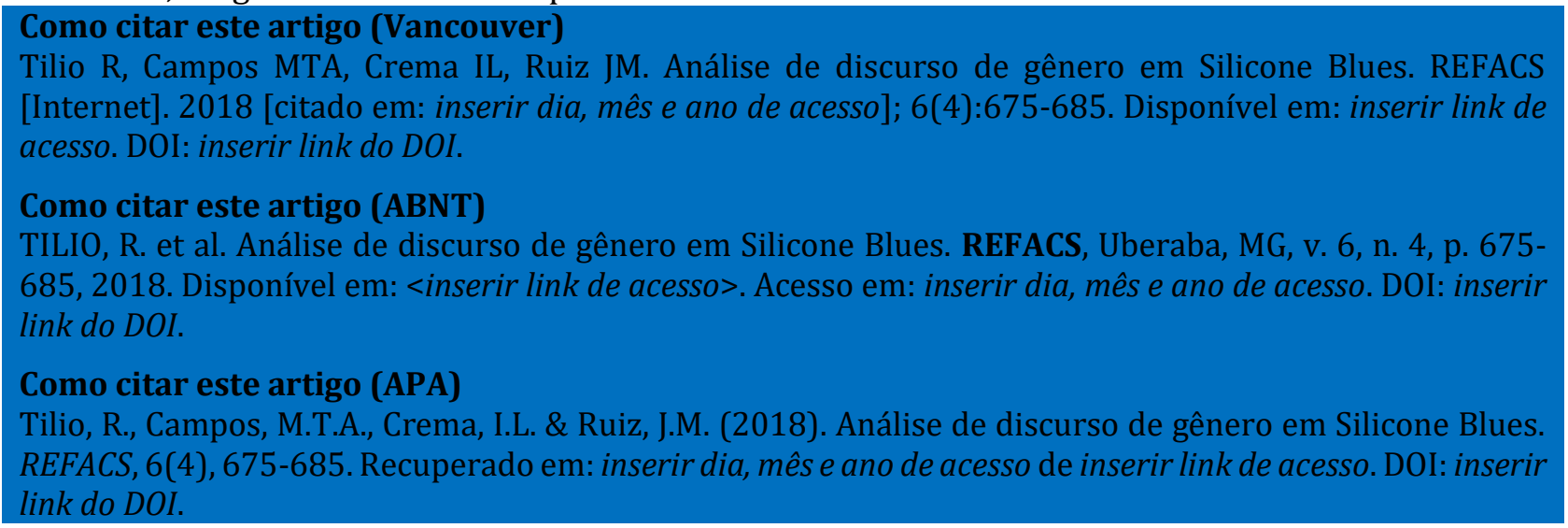

